\title{
Critical airway involvement in relapsing polychondritis
}

\author{
Camilla Gorard, ${ }^{1}$ Saleheen Kadri ${ }^{2}$
}

${ }^{1}$ Medical School, University of Bristol, Bristol, UK ${ }^{2}$ Department of Respiratory Medicine, Gloucestershire Royal Hospital, Gloucester, UK

\section{Correspondence to}

Camilla Gorard, cg0021@bristol.ac.uk

Accepted 10 August 2014

\section{SUMMARY}

Relapsing polychondritis (RP) is a rare multisystem disease characterised by progressive inflammation and destruction of cartilaginous structures. Airway involvement in RP occurs in approximately $50 \%$ of cases. We present a 70-year-old woman with a diagnosis of early adult onset asthma. She required multiple hospital admissions for recurrent episodes of acute severe dyspnoea for 1 year. These were treated as asthma. Months later she developed saddle nose deformity and hoarseness of voice. CT revealed tracheal/bronchial wall thickening and luminal narrowing. Based on these findings, RP was diagnosed. Insertion of a tracheobronchial stent was necessary due to severe tracheobronchomalacia. This intervention improved the patient's dyspnoea immediately. This case is reported to raise awareness of airway involvement in RP and discuss its current management. Early diagnosis of RP is essential to allow prompt treatment and to decrease the risk of life-threatening airway collapse.

\section{BACKGROUND}

Relapsing polychondritis (RP) was first described as 'polychondropathia' by Jaksch-Wartenhorst in 1923. ${ }^{1}$ RP is a multisystem relapsing-remitting disease of unknown aetiology with episodes of recurrent inflammation of cartilaginous structures. Common cartilaginous tissues involved are: laryngotracheobronchial tree, pinna, nose and peripheral joints. Non-cartilaginous tissues such as the skin, eyes and cardiovascular system can also be damaged.

There are approximately 600 cases of RP reported worldwide. ${ }^{2} \mathrm{RP}$ is a challenging condition to diagnose; symptoms vary and it often goes misdiagnosed. We report a case of RP who presented atypically and posed a great diagnostic challenge.

\section{CASE PRESENTATION}

A 70-year-old-woman presented with 3-day history of acute worsening dyspnoea, chest tightness, anterior neck pain and cough productive of white sputum. She had been experiencing worsening breathlessness; and was housebound for the preceding year due to limited exercise tolerance.

She had been admitted to hospital twice during the previous 6 months for presumed exacerbations of asthma. Improvement was observed following treatment with steroids, nebulisers, antibiotics and aminophylline. Chest radiographs on these admissions revealed areas of streaky opacification in the left lower lobe, representing infection or atelectasis.

She was diagnosed with asthma at the age of 21 years on the basis of suggestive symptoms, $20 \%$ diurnal variation of peak expiratory flow rate (PEFR) and clinical response to bronchodilator and steroid therapy. Her asthma had been well controlled until 2 years ago. She is a life-long non-smoker.

On this admission, she was distressed with a high respiratory rate of 32 breaths $/ \mathrm{min}$. $\mathrm{O}_{2}$ saturation was $93 \%$ on $4.0 \mathrm{~L} \mathrm{O}_{2} / \mathrm{min}$. PEFR was $150 \mathrm{~L} / \mathrm{min}$ which was $43 \%$ of her normal PEFR. Respiratory examination revealed symmetrically reduced chest expansion, dull percussion note at the left lung base and global expiratory wheeze. Chest radiograph was unremarkable. Inflammatory markers were mildly elevated.

She improved with standard asthma therapy of salbutamol nebulisers, antibiotics, intravenous hydrocortisone, magnesium sulfate and aminophylline. However, 1 week following admission, she deteriorated acutely with dyspnoea. Chest radiograph now revealed increased density in both lower lobes. Associated markedly elevated inflammatory markers also indicated superimposed infection. She was transferred to the intensive care unit requiring invasive ventilation and ultimately a percutaneous tracheostomy. An echocardiogram during this admission was unremarkable with normal biventricular function. High-resolution CT of the chest did not show any evidence of interstitial pneumonitis. The patient's condition eventually improved and she was discharged 3 weeks later.

Two months later she developed hoarseness of voice and saddle nose deformity (figure 1); and was therefore readmitted for further investigation. Further questioning revealed that she had been experiencing pain in her nose and anterior ribcage for the past year, indicating nasal chondritis and costochondritis, respectively.

\section{INVESTIGATIONS}

CT of the chest revealed diffuse thickening and luminal narrowing of the distal trachea and main bronchi (figure 2). Bronchoscopy showed tracheobronchomalacia, tracheobronchial wall inflammation and disappearance of tracheobronchial cartilage rings.

Positron emission tomography identified inflammation of multiple cartilaginous structures. Fluorine-18 deoxyglucose uptake was increased in the nasal cartilages, rib cartilages and tracheobronchial tree. A cartilage biopsy from her nasal septum showed non-specific inflammatory changes. However, a transbronchial biopsy demonstrated 'collagen necrobiosis' indicating RP. 


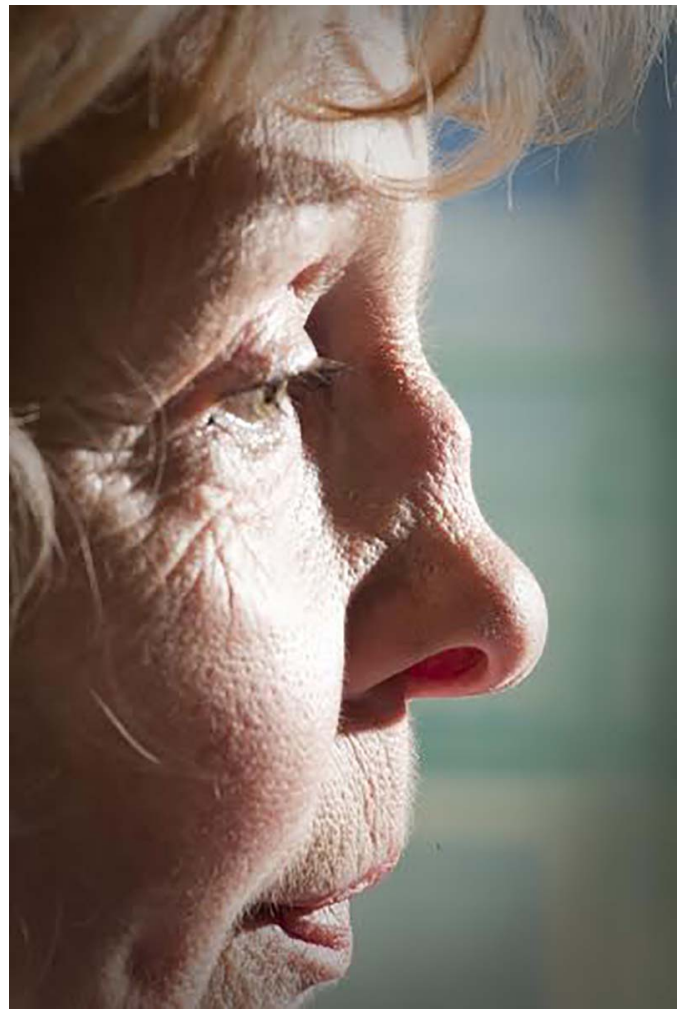

Figure 1 Saddle nose deformity in the patient.

\section{TREATMENT}

The patient's clinical features and imaging pointed to a diagnosis of RP. She was given $500 \mathrm{mg}$ intravenous methylprednisolone daily for 3 days. Subsequently she received $60 \mathrm{mg}$ oral prednisolone and $100 \mathrm{mg}$ cyclophosphamide daily. Prednisolone was then slowly weaned.

Two months later, because of significant airway obstruction (tracheobronchomalacia), a self-expanding metallic stent (SEMS) was inserted at bronchoscopy. A SEM trouser stent was positioned in the trachea with the proximal end at the level of the mid-T2 vertebra and the distal limbs extending into the left and right main bronchi.

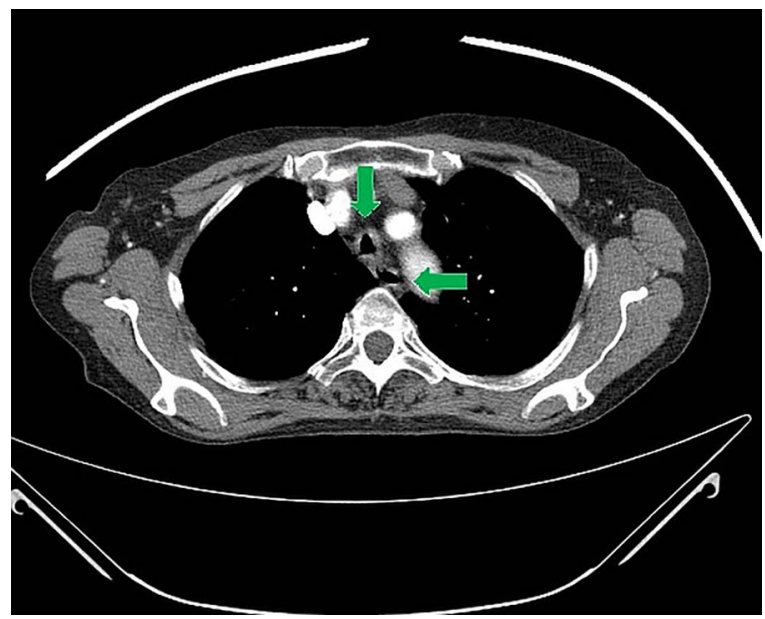

Figure 2 CT of the chest (in expiration) of the patient showing thickening and luminal narrowing of the main bronchi; indicated by arrows.

\section{OUTCOME AND FOLLOW-UP}

Following tracheobronchial stent insertion, her respiratory symptoms and physical functional status improved significantly and she was discharged. Immediately prior to stent insertion a pulmonary function test showed that forced expiratory volume in $1 \mathrm{sec}\left(\mathrm{FEV}_{1}\right)$ was $0.74 \mathrm{~L}$ (39\% predicted), forced vital capacity (FVC) was $2.56 \mathrm{~L}$ (110\% predicted) and $\mathrm{FEV}_{1} / \mathrm{FVC}$ ratio was $29 \%$. A pulmonary function test immediately following stent insertion is unavailable as she was too unwell to do this.

Unfortunately 2 months later she presented again with acute severe dyspnoea and wheeze. Clinically there were coarse crackles and dull percussion note at her left lung base. Chest radiograph featured collapse of the lower lobe of left lung (figure 3).

Bronchoscopy revealed obstruction of the bronchial limb of the stent with thick mucus secretions. Distal to the stent the airways had collapsed and the bronchial mucosa was inflamed. Repeated bronchoscopies were performed to evacuate the thick mucus secretions. Associated infections were treated with antibiotics and she remained on maintenance immunosuppressive therapy. The patient developed extreme anxiety and palliative care input was sought regarding this. However, her symptoms gradually improved and she was discharged home.

Currently she is being closely monitored as an outpatient. Her latest pulmonary function test from March 2014 showed that $\mathrm{FEV}_{1}$ was $0.66 \mathrm{~L}$ (35\% predicted), FVC was $1.83 \mathrm{~L}(80 \%$ predicted) and $\mathrm{FEV}_{1} / \mathrm{FVC}$ ratio was $36 \%$.

\section{DISCUSSION}

Literature on RP is sparse. The incidence is approximately 3.5 per $1000000 .^{2} 3 \mathrm{RP}$ has a peak incidence between 4060 years, but can occur at any age. ${ }^{4}$ Although RP affects men and women equally, severe airway manifestations are three times more likely in women. ${ }^{4}$

The exact aetiology of RP is unknown. It is an immunemediated disease most likely targeting type II collagen found mainly in cartilaginous structures and the eye. ${ }^{5} 6$ Antitype II collagen antibodies are found in about a third of patients.

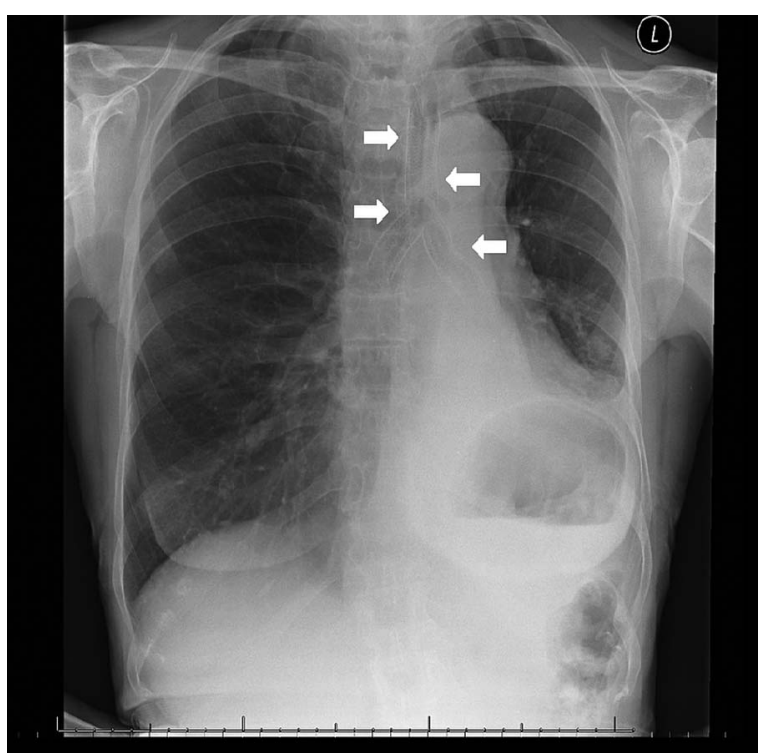

Figure 3 Chest radiograph of the patient showing left lower lobe collapse and evidence of obstruction. The tracheobronchial stent is indicated by arrows. 
Box 1 Summary of 6 diagnostic criteria for relapsing polychondritis ${ }^{4}$

Diagnostic criteria for relapsing polychondritis ( $\geq 3$ for diagnosis) Recurrent chondritis of both auricles

Seronegative inflammatory arthritis

Nasal chondritis

Inflammation of ocular structures

Chondritis of respiratory tract

Cochlear and/or vestibular damage (hearing loss, tinnitus, vertigo)

On average it takes 3 years between manifestation of the first symptom to RP diagnosis. ${ }^{7}$ Currently, no specific diagnostic tests for RP exist; and diagnosis relies largely on clinical features. Six diagnostic criteria of RP have been established which are summarised in box $10^{3}{ }^{4}$ Diagnosis of RP is made by the presence of three or more of these clinical criteria; or one clinical criterion and histological confirmation; or chondritis in two or more sites with treatment response. ${ }^{348}$

In almost all patients the presenting symptom is auricular chondritis. ${ }^{4}$ Arthralgia, with or without arthritis is the second commonest presenting symptom. ${ }^{4}$ It is noteworthy that neither of these symptoms occurred in the present patient. This makes this case of RP atypical.

Airway involvement while uncommon at presentation, occurs in approximately $50 \%$ of patients with $\mathrm{RP}^{9}{ }^{9}$ Clinical manifestations of RP with airway involvement include dyspnoea, cough, wheeze, stridor, hoarseness and aphonia. ${ }^{10}$ Tracheomalacia, bronchomalacia or tracheobronchomalacia is caused by recurrent airway chondritis and is associated with poor prognosis. ${ }^{11}$ Airway manifestations are the commonest cause of morbidity and mortality in $\mathrm{RP}^{3}{ }^{4}$

The patient presented here was diagnosed with severe exacerbations of asthma prior to diagnosis of RP. This is not the first case of RP misdiagnosed as asthma. ${ }^{12-16}$ Reasons for delayed diagnosis in the present patient include: (1) transient improvement with steroid therapy, (2) dyspnoea and cough were the presenting symptoms, (3) absence of auricular chondritis and arthralgia (she however had non-specific costochondritis) and (4) late development of saddle nose deformity. Other case reports deduce similar reasons for airway involvement in RP misdiagnosed as asthma. ${ }^{12} 17$

For these reasons it is imperative that RP is distinguished from asthma, to aid management and prevent severe airway manifestations. In RP (unlike asthma), inhaled corticosteroids and bronchodilators are ineffective, spirometry demonstrates upper airway obstruction, CT imaging can reveal thickening and stenosis of the airways, and bronchoscopy can show inflammation, narrowing or collapse of the airways. ${ }^{9} 121819$

Moreover it is essential to examine the auricle, nose and joints in patients presenting with asthma attack-like symptoms to differentiate between these airway diseases.

Currently there is no standard treatment for RP. No clinical trials have been carried out due to its rarity. Therefore, current medical therapy for RP is largely empirical and established on case reports. ${ }^{20}$ Despite this, RP generally responds to steroids and other immunosuppressive agents.

Corticosteroids are first-line therapy. They reduce severity and frequency of relapses. ${ }^{20}{ }^{21} \mathrm{~A}$ low maintenance dose of steroid is used to prevent relapse and the dose is increased during flare ups. However, there is no evidence that corticosteroids alter the natural progression of RP. Steroid-sparing agents such as cyclophosphamide, methotrexate, azathioprine and cyclosporine, are also used and seem to help. ${ }^{22}$ To date there is no evidence that one is more effective at preventing exacerbations than another. ${ }^{23}$

Initial case reports suggest some biological therapies are of use in RP, namely tumour necrotic factor- $\alpha$ (TNF- $\alpha$ ) and anti-CD4 monoclonal antibodies. ${ }^{24}{ }^{25} \mathrm{~A}$ case report describes complete remission of RP with airway involvement following administration of infliximab (TNF- $\alpha$ antibody), used in other immune-mediated diseases including Crohn's disease and rheumatoid arthritis. ${ }^{25}$ Complete remission was also reported in patients with severe airway RP following autologous stem cell transplantation or administration of oral bovine type II collagen. ${ }^{26}{ }^{27}$ However, these case reports of successful novel therapies may be coincidental since RP is relapsing-remitting. Clinical trials and longer follow-ups are required to test these potential therapies for RP.

Failure of early diagnosis of airway involvement in RP can lead to irreversible cartilage damage. Steroids or other immunosuppressants are ineffective in these advanced cases. ${ }^{28}$ Instead airway interventions are required such as, balloon dilation, tracheobronchial stents, tracheostomy or tracheal and laryngotracheal reconstructions.

Tracheobronchial stents in patients with major airway stenosis or collapse can be a life-saving option. Stents maintain airway patency and prevent airway collapse. They can alleviate airflow obstructions caused by RP and provide immediate symptomatic relief. ${ }^{9}$ Numerous studies report immediate improvement in dyspnoea following stent insertion, with some patients even returning to their normal active lifestyle. ${ }^{9} 1128$ Thus they can provide chronic palliation.

The two main types of stents are silicone or SEMS. SEMS are permanent while silicone stents more readily removed. The optimal type of airway stent and ideal timing of its placement remains enigmatic. ${ }^{11}$ Complications of airway stenting include aspiration pneumonia, tracheobronchial wall erosion, granulation tissue formation, secretion retention and recurrent infection. ${ }^{29} 30$ In view of these potential complications stents are only inserted in patients who are unresponsive to medical therapy. ${ }^{31}$

Awareness of early airway involvement in RP is essential for prompt diagnosis and allows treatment to prevent lifethreatening airway collapse. High-dose corticosteroids are used to prevent and delay irreversible airway cartilage loss. However, once cartilage is lost, airway stenting is required to maintain airway patency.

\section{Learning points}

- Relapsing polychondritis (RP) is a rare condition characterised by recurrent inflammation and destruction of cartilaginous structures.

- RP is a challenging clinical diagnosis and often overlooked.

- Asthma can mimic RP when the airways are involved.

- Airway involvement in RP requires corticosteroids/ immunosuppressants and if severe may require tracheal and/ or bronchial stenting.

Acknowledgements The authors thank Dr Andrew White, Department of Respiratory Medicine, Gloucestershire Royal Hospital, Gloucester.

Contributors CG wrote the first draft. SK revised manuscript. 


\section{Competing interests None.}

Patient consent Obtained.

Provenance and peer review Not commissioned; externally peer reviewed.

\section{REFERENCES}

1 Jaksch-Wartenhorst R. Polychondropathia. Wien Arch F Inn Med 1923;6:93-100.

2 Luthra HS. Relapsing polychondritis. In: Klippel JH, Dieppe PA, eds. Rheumatology. St. Louis, Mosby. 1998:1-4.

3 Michet CJ, McKenna CH, Luthra HS, et al. Relapsing polychondritis. Survival and predictive role of early disease manifestations. Ann Intern Med 1986;104:74-8.

4 McAdam LP, O'Hanlan MA, Bluestone $R$, et al. Relapsing polychondritis: Prospective study of 23 patients and a review of the literature. Medicine 1976:55:193-215.

5 Foidart JM, Abe S, Martin GR, et al. Antibodies to type-Il collagen in relapsing polychondritis. N Eng J Med 1978;299:1203-7.

6 Saxne T, Heinegard D. Serum concentrations of 2 cartilage matrix proteins reflecting different aspects of cartilage turnover in relapsing polychondritis. Arthritis Rheum 1995;38:294-6.

7 Trentham DE, Le CH. Relapsing polychondritis. Ann Internal Med 1998;129:114-22.

8 Damiani JM, Levine HL. Relapsing polychondritis-report of 10 cases. Laryngoscope 1979:89:929-46.

9 Hong G, Kim H. Clinical characteristics and treatment outcomes of patients with relapsing polychondritis with airway involvement. Clin Rheumatol 2013;32:1329-35.

10 Tsunezuka Y, Sato H, Shimizu H. Tracheobronchial involvement in relapsing polychondritis. Respiration 2000;67:320-2.

11 Sarodia BD, Dasgupta A, Mehta AC. Management of airway manifestations of relapsing polychondritis:case reports and review of literature. Chest 1999;116:1669-75.

12 Sato R, Ohshima N, Masuda $\mathrm{K}$, et al. A patient with relapsing polychondritis who had been diagnosed as intractable bronchial asthma. Intern Med 2012;51:1773-8.

13 Miyazaki $H$, Shimane $S$, Morita $S$, et al. Placement of an ultraflex nitinol stent for severe tracheobronchial obstruction in a case of relapsing polychondritis. Nihon Kokyuki Gakkai Zasshi 2005;43:328-32.

14 Chang SJ, Lu CC, Chung YM, et al. Laryngotracheal involvement as the initial manifestation of relapsing polychondritis. J Chin Med Assoc 2005;68:279-82.
15 Watanabe $\mathrm{Y}$, Miwa $\mathrm{C}$, Tubochi $\mathrm{H}$, et al. A case of airway-limiting type relapsing polychondritis. Nihon Kokyuki Gakkai Zasshi 2007;45:987-91.

16 Segel MJ, Godfrey S, Berkman N. Relapsing polychondritis: reversible airway obstruction is not always asthma. Mayo Clin Proc 2004;79:407-9.

17 Mohammad A, Ambrose N, Tuohy M, et al. Relapsing polychondritis: reversible airway obstruction or asthma. Clin Exp Rheumatol 2008;26:938-40.

18 Mohsenifar Z, Tashkin DP, Carson SA, et al. Pulmonary function in patients with relapsing polychondritis. Chest 1982;81:711-17.

19 Behar JV, Choi YW, Hartman TA, et al. Relapsing polychondritis affecting the lower respiratory tract. AJR Am J Roentgenol 2002;178:173-7.

20 Letko E, Zafirakis $P$, Baltatzis $S$, et al. Relapsing polychondritis: a clinical review. Semin Arthritis Rheum 2002;31:384-95.

21 Kent PD, Michet CJ Jr, Luthra HS. Relapsing polychondritis. Curr Opin Rheumatol 2004;16:56-61.

22 Yoo JH, Chodosh J, Dana R. Relapsing polychondritis: systemic and ocular manifestations, differential diagnosis, management, and prognosis. Semin Ophthalmol 2011;26:261-9.

23 Staats BA, Utz JP, Michet CJ. Relapsing polychondritis. Semin Resp Crit Care Med 2002;23:145-54.

24 Choy EHS, Chikanza IC, Kingsley GH, et al. Chimeric anti-CD4 monoclonal antibody for relapsing polychondritis. Lancet 1991;338:450.

25 Mpofu S, Estrach C, Curtis J, et al. Treatment of respiratory complications in recalcitrant relapsing polychondritis with infliximab. Rheumatology 2003;42:1117-8.

26 Rosen 0 , Thiel A, Massenkeil G, et al. Autologous stem-cell transplantation in refractory autoimmune diseases after in vivo immunoablation and ex vivo depletion of mononuclear cells. Arthritis Res 2000;2:327-36.

27 Navarro MJ, Higgins GC, Lohr KM, et al. Amelioration of relapsing polychondritis in a child treated with oral collagen. Am J Med Sci 2002;324:101-3.

28 Zhang J-Q, Li Q, Bai C, et al. Clinical features and treatment of relapsing polychondritis with involvement of the respiratory tract-report of thirteen cases. Zhonghua Jiehe He Huxi Zazhi 2007;30:173-7.

29 Nesbitt JC, Carrasco H. Expandable stents. Chest Surg Clin N Am 1996;6:305-28.

30 Xie C, Shah N, Shah PL, et al. Laryngotracheal reconstruction for relapsing polychondritis: case report and review of the literature. J Laryngol Otol 2013;127:932-5

31 Chapron J, Wermert D, Le Pimpec-Barthes F, et al. Bronchial rupture related to endobronchial stenting in relapsing polychondritis. Eur Resp Rev 2012;21:367-9.

Copyright 2014 BMJ Publishing Group. All rights reserved. For permission to reuse any of this content visit http://group.bmj.com/group/rights-licensing/permissions.

BMJ Case Report Fellows may re-use this article for personal use and teaching without any further permission.

Become a Fellow of BMJ Case Reports today and you can:

- Submit as many cases as you like

- Enjoy fast sympathetic peer review and rapid publication of accepted articles

- Access all the published articles

- Re-use any of the published material for personal use and teaching without further permission

For information on Institutional Fellowships contact consortiasales@bmjgroup.com

Visit casereports.bmj.com for more articles like this and to become a Fellow 